\title{
Does Croton Argyrophyllus Extract Has an Effect on Muscle Damage and Lipid Peroxidation in Rats Submitted to High Intensity Strength Exercise?
}

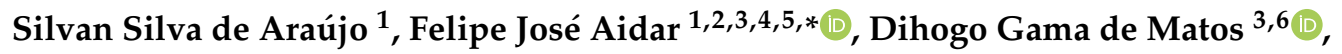 \\ Jymmys Lopes dos Santos ${ }^{7}$, Lúcio Marques Vieira Souza ${ }^{7}$, Albená Nunes da Silva ${ }^{8}$, \\ Rodrigo Miguel dos Santos 2,9 (D), Anderson Carlos Marçal ${ }^{1}$, Daniella Mota Mourão ${ }^{10}$, \\ Amário Lessa Júnior ${ }^{11}$, Geraldo Magela Durães ${ }^{11}$, André Luiz Gomes Carneiro ${ }^{11}$, \\ Rodrigo Gonçalves da Silva ${ }^{12}$, Mauro Martins Teixeira ${ }^{13}$ and Charles dos Santos Estevam ${ }^{5,7}$ \\ 1 Post-Graduate Program in Physical Education, Federal University of Sergipe, São Cristóvão SE 49100-000, \\ Brazil; silvan.ssa@gmail.com (S.S.d.A.); acmarcal@yahoo.com.br (A.C.M.) \\ 2 Post-Graduate Program in Physiological Sciences, Federal University of Sergipe, São Cristóvão SE 49100-000, \\ Brazil; rms.edf@hotmail.com \\ 3 Group of Studies and Research of Performance, Sport, Health and Paralympic Sports-GEPEPS, \\ Federal University of Sergipe, São Cristovão, Sergipe 49100-000, Brazil; dihogogmc@hotmail.com \\ 4 Department of Physical Education, Federal University of Sergipe, São Cristóvão, Sergipe 49100-000, Brazil \\ 5 Department of Physiology, Federal University of Sergipe, São Cristóvão, SE 49100-000, Brazil; \\ cse.ufs@gmail.com \\ 6 Institute of Parasitology, McGill University, Montreal, QC H9X 3V9, Canada \\ 7 Post-Graduate Program in Biotechnology, Northeast Network in Biotechnology (RENORBIO), \\ Federal University of Sergipe, São Cristóvão SE 49100-000, Brazil; jymmyslopes@yahoo.com.br (J.L.d.S.); \\ profedf.luciomarkes@gmail.com (L.M.V.S.) \\ 8 Exercise's Inflammation and Immunology Laboratory, Sports Center, Federal University of Ouro Preto, \\ Minas Gerais 35400-000, Brazil; albenanunes@hotmail.com \\ 9 Department of Circulation and Medical Imaging, St. Olav's Hospital, Norwegian University of Science and \\ Technology (NTNU), NO-0508 Trondheim, Norway \\ 10 Department of Medical Clinic, State University of Montes Claros, Montes Claros, MG 39401-089, Brazil; \\ daniella_mourao@hotmail.com \\ 11 Department of Physical Education, State University of Montes Claros, Montes Claros, MG 39401-089, Brazil; \\ lessauni@gmail.com (A.L.J.); gmdmoc@yahoo.com.br (G.M.D.); algcarneiro@gmail.com (A.L.G.C.) \\ 12 Department of Physical Education, University Funorte of Montes Claros, \\ Montes Claros, MG 39401-089, Brazil; rodrigo.edfisio@yahoo.com.br \\ 13 Department of Pathology, Institute of Biological Sciences, Federal University of Minas Gerais, \\ Belo Horizonte 31270-901, Brazil; mmtex.ufmg@gmail.com \\ * Correspondence: fjaidar@gmail.com; Tel.: +55-79-2105-6600 or +55-79-2105-6537
}

Received: 18 September 2019; Accepted: 15 October 2019; Published: 31 October 2019

Abstract: Many species of the genus Croton have been used for anti-inflammatory, antiproliferative, antidiabetic, and antitumor purposes. The objective was to evaluate the effect of a hydroethanolic extract (HEE) from the inner bark of Croton argyrophyllus (Euphorbiaceae) on muscle damage and oxidative stress in rats after high intensity exercise. The animals were divided into four groups: (i) the sedentary group (SV; $n=7$ ), (ii) the exercise vehicle group ( $\mathrm{EV}, n=7$ ), (iii) the sedentary group HEE (SHG; $n=7$ ) composed of sedentary animals and treated with the hydroethanolic extract of C. argyrophyllus ( $200 \mathrm{mg} / \mathrm{kg}$, v.o.), and (iv) the HEE exercise group (HEE; $n=7$ ) composed of animals submitted to resistance exercise (RE) and treated with the hydroethanolic extract of $C$. argyrophyllus (200 mg/kg, v.o.). In the 2,2-Diphenyl-1-picrylhydrazyl (DPPH) test, the HEE showed lower values of inhibition potential (IP\%) at 39.79\% compared to gallic acid, 87.61\%, and lipoperoxidation inhibition at $27.4 \%(100 \mu \mathrm{g} / \mathrm{mL})$ or $28.6 \%(200 \mu \mathrm{g} / \mathrm{mL})(p<0.001)$. There was inhibition in free radicals in vivo. The HEE of $C$. argyrophyllus partially reduced the biomarkers of oxidative stress in muscle tissue and 
muscular damage (creatine kinase (CK) and Lactate Dehydrogenase (LDH)) $(p<0.05)$ in rats, and in this sense it can be an aid to the recovery process after exhaustive efforts.

Keywords: strength exercise; croton; oxidative stress; muscle damage; lipoperoxidation; hidroethanol extract

\section{Introduction}

Resistance exercise (RE) is characterized as a physical activity involving voluntary actions of the skeletal muscle in a given body segment against an external resistance [1]. The execution of high intensity or exhaustive RE can result in injuries and chronic fatigue in part due to the imbalance between the production of reactive oxygen species (ROS) and endogenous antioxidant activity [2]. Although it is established that optimal production of ROS is important to induce muscle contraction, high concentrations of ROS accelerate the process of exercise-induced muscle fatigue [3,4].

Some environmental factors can challenge the cellular antioxidant defense system, including physical exercise, and especially high intensity exercise. Accordingly, exhaustive exercise sessions lead to an imbalance between the antioxidant system and the free radicals formed during the oxidative metabolism due to ischemia-reperfusion during each set of cyclical contractions [5]. In turn, oxidative stress can cause damage to cell structures and macromolecules such as lipids, proteins, and nucleic acids, which result in a loss of physical performance and muscle injuries $[2,5,6]$.

The physiological functionality of the systems during intense exposure to acute exercise can be extended by supplemental antioxidants, such as those found in medicinal plants [7]. Since free radicals are unstable molecules that feature unpaired electrons, they can be inhibited by isolated plant phenolic compounds, such as flavonoids [7]. These substances, due to their redox ability, can neutralize oxidative free radical activity $[8,9]$, reinforcing the cellular antioxidant system composed of the enzymes superoxide dismutase (SOD), catalase (CAT), and the system glutathione peroxidase/glutathione reductase $(\mathrm{GPX} / \mathrm{GR})$, which maintains an appropriate balance between catabolic and anabolic processes [10].

Croton argyrophyllus extracts are widely distributed and consumed therapeutically in the semi-arid northeast. In addition, two new casbane diterpenes (1 and 2 ) of Croton argyrophyllus, an abundant shrub in the northeastern region of Brazil, have been reported to have been isolated, which has shown a marked increase as an ethnobotanical treatment of heart diseases and as a tranquilizer [11], although there is still much to clarify in regards to the protective redox effects of their extracts and other secondary metabolites on oxidative stress related to exercise. In this context, the objective of this study was to evaluate the effect of a crude extract from the inner bark of $C$. argyrophyllus on on muscle damage and oxidative stress in female rats performing high-intensity exercises.

\section{Materials and Methods}

\subsection{Plant Material Collection}

The inner bark of the plant $C$. argyrophyllus $(1.5 \mathrm{~kg})$ was obtained in the city of Olho d'Água do Casado, Alagoas $\left(09^{\circ} 25^{\prime} 00^{\prime \prime} \mathrm{S}, 38^{\circ} 01^{\prime} 11^{\prime \prime} \mathrm{W}\right)$. It was then subjected to oven drying $\left(37^{\circ} \mathrm{C}\right)$, crushed, and reduced to a powder. The resulting powder was macerated in ethanol $(90 \% \mathrm{v} / \mathrm{v})$ at $25^{\circ} \mathrm{C}$ yielding the hydroethanolic extract (HEE). The HEE was concentrated in a rotary evaporator (Logen Scientific ${ }^{\circledR}$, Lagos, Nigeria) under reduced pressure at $50{ }^{\circ} \mathrm{C}$ until achieving the final desired volume, yielding $73.3 \mathrm{~g}$ of HEE. The dried extract was stored in a glass bottle and preserved in a freezer at $-30^{\circ} \mathrm{C}$. 


\subsection{High-Performance Liquid Chromatography (HPLC)}

To test for the presence of organic compounds available in the HEE, we used a Shimadzu high performance liquid chromatography (HPLC) (Prominence model, Kyoto, Japan). This HPLC consists of a model DGU-20A3 vacuum cleaner, LC-6A high pressure pumps, and photodiode array (PDA) detection system coupled with Interface CBM 20A. Data acquisition and processing was performed using LC Solution software. The analysis was performed on a Phenomenex LUNAs analytical column C18 column $(250 \times 4.6 \mathrm{~mm}$ i.d., $5 \mu \mathrm{m}$ particle diameter, Phenomenex, Torrance, CA, USA). Separations of the components were performed on a reverse phase elution gradient, which emphasizes the polar compounds [12]. To that end, $20 \mu \mathrm{L}$ of HEE $\left(1 \mathrm{mg} \cdot \mathrm{mL}^{-1}\right)$, previously membrane filtered at $0.20 \mu \mathrm{m}$ in diameter, was injected into the mobile phase HPLC, which consisted of water and acetonitrile, both acidified with acetic acid. The elution was characterized as isocratic: 70:30:0.5\%. The detection was performed in the UV spectra and obtained at a range of $250 \mathrm{~nm}$ to $350 \mathrm{~nm}$.

\subsection{Antioxidant Activity In Vitro}

HEE was dissolved in methanol to obtain a stock solution of $500 \mu \mathrm{g} / \mathrm{mL}$, from which aliquots were removed and added to a solution of 2,2-diphenyl-1-picrilhidrazina (DPPH) $(40 \mu \mathrm{g} / \mathrm{mL})$ at concentrations of $60,90,120,150$, and $180 \mu \mathrm{g} / \mathrm{mL}$. The dilutions of the positive control, gallic acid, led to concentrations of $1-10 \mu \mathrm{g} / \mathrm{m}$, with all reaction solutions in a final volume of $3 \mathrm{~mL}$. A mixture of methanol $(2.7 \mathrm{~mL})$ and HEE $(0.3 \mathrm{~mL})$ was used as the blank. Measures of absorbance were made at $515 \mathrm{~nm}$ at 1, 5, and $10 \mathrm{~min}$, and then every $10 \mathrm{~min}$ up to $1 \mathrm{~h}$ [13]. The percentage of the remaining DPPH (DPPHREM\%) was calculated according to the method of Souza et al., [13] using the equation: \%DPPHREM = $(\mathrm{DPPH}) \mathrm{T} /(\mathrm{DPPH}) \mathrm{T} 0 \times 100$, where $(\mathrm{DPPH}) \mathrm{T}$ is the concentration of DPPH in the middle, after the reaction with the sample, and (DPPH)T0 is the initial concentration of DPPH, namely $40 \mu \mathrm{g} / \mathrm{mL}$ $(100 \mathrm{mmol} / \mathrm{mL})$. The effective concentration required to decrease the initial concentration of DPPH by $50 \%$ (EC50) was calculated by plotting the \%DPPHREM over $60 \mathrm{~min}$ in opposition to the sample concentrations. The results are expressed in $\mu \mathrm{g} / \mathrm{mL} \pm$ standard deviation. The higher the consumption of DPPH per sample, the lower its EC50, and the higher its antioxidant activity. The ratio of the DPPH concentration to the EC50 can be obtained by the antioxidant activity index $(\mathrm{AAI}=(\mathrm{DPPH}) / \mathrm{EC} 50)$, which Scherer and Godoy [14] consider the best expression of the antioxidant capacity.

\subsection{Lipoperoxidation}

The ability to inhibit lipid peroxidation was determined by measurement of thiobarbituric acid reactive substances (TBARS) in a test tube, and a lipid matrix composed of egg yolk (1 mL) was homogenized in $99 \mathrm{~mL}$ of phosphate buffer $7.4(20 \mathrm{mM})$ [15]. The quantification of TBARS was performed according to Lapenna et al. [16] and Sanocka and Kurpisz [17]. The test tubes containing the reaction mixtures were incubated at $37^{\circ} \mathrm{C}$ for $30 \mathrm{~min}$ to generate oxidative damage. Then, $500 \mu \mathrm{L}$ of trichloroacetic acid (TCA 15\%) was added for precipitation of the proteins, which were removed by centrifugation $(2000 \mathrm{rpm}, 10 \mathrm{~min})$. The supernatant was collected and $500 \mu \mathrm{L}$ of thiobarbituric acid (TBA $0.67 \%$ ) was added to the test tubes. These were incubated at $95^{\circ} \mathrm{C}$ for $60 \mathrm{~min}$. Then, absorbance measurements were performed at a wavelength of $532 \mathrm{~nm}$.

All tests were performed in triplicate and compared to the standard antioxidant performance, trolox, at the same concentrations of the samples. The molar extinction coefficient $1.54 \times 105 \mathrm{M}^{-1} \mathrm{~cm}^{-1}$ and TBARS was expressed as nmol Eq. MDA mL ${ }^{-1}$ plasma.

\subsection{Experimental Group}

The animals were divided into four groups: (i) the sedentary vehicle group (SG; $n=7$ ) composed of sedentary vehicle-treated animals (Tween 80 , orally (v.o.)), (ii) the exercise vehicle group (EG, $n=7$ ) composed of animals treated with the vehicle (Tween 80, v.o.) and submitted to RE, (iii) the sedentary group HEE (SHG; $n=7$ ) composed of sedentary animals and treated with the hydroethanolic extract 
of C. argyrophyllus ( $200 \mathrm{mg} / \mathrm{kg}$, v.o.), and (iv) the HEE exercise group (EHG; $n=7$ ) composed of animals submitted to RE and treated with the hydroethanolic extract of C. argyrophyllus ( $200 \mathrm{mg} / \mathrm{kg}$, v.o.) see Figure 1.

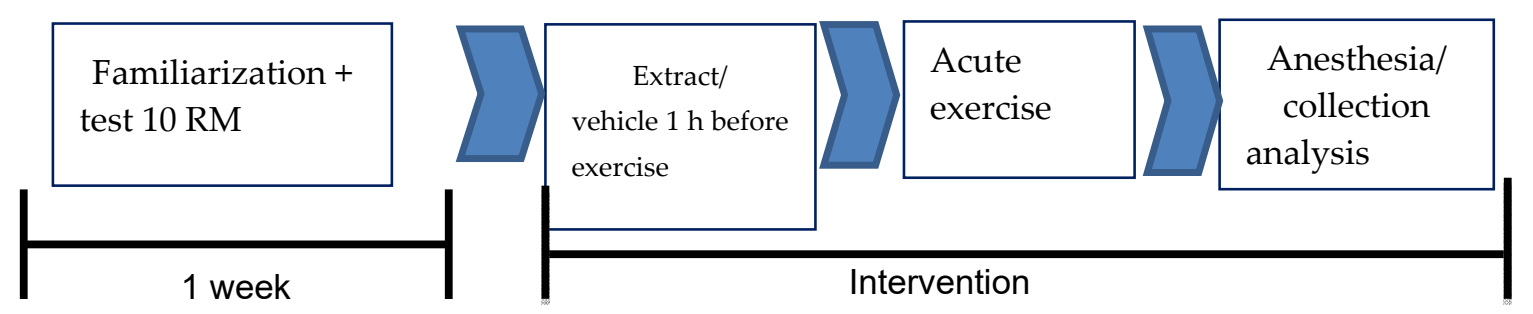

Figure 1. Diagram of the experimental protocol.

\subsection{Resistance Exercise Model Adapted to Rats}

The hind limbs of rats in the exercise groups were submitted to a single intense workout in a weight lifting technique previously described in detail [18]. Each animal was wearing a leather jacket attached to a wooden bar (support), which was connected at the other end to a fulcrum fixed to a wooden base. The animal, therefore, from an upright and supported position with its back foot on the table, ran to full extension of its legs (looking for a jump), and then was electrically stimulated in its tail $(10 \mathrm{~V}, 100 \mathrm{~Hz}$, for $3 \mathrm{~s})$. For electrical stimulation, we used self-adhesive electrodes (ValuTrode brand, model CF3200, Santa Tereza do Oeste, Brazil, size $3.2 \mathrm{~cm}$, placed on the tail and connected to a stimulator) (BIOSET, Physiotonus Four, Model 3050, Rio Claro, São Paulo, Brazil). These parameters were adopted because they are associated with changes in the levels of catecholamines, sympathetic activity, and adrenal hypertrophy [19].

The overhead consisted of lead plates embedded in the support. The animals were previously adapted to the device for a week, including those groups not exercised (VS and ES). Supplementation with hydroethanolic extract of $C$. argyrophyllus was began one hour before the start of the session. The session involved multiple sets of 10 reps with a 1 min interval between each series until exhaustion. The first set surveys were given with a load of $500 \mathrm{~g}$. In subsequent sets, a load of $500 \mathrm{~g}$ was added until the rat could not complete 10 repetitions. In this case, the load was then adjusted in increments or decreases of $100 \mathrm{~g}$ to meet the maximum load when 10 repetitions could be performed, and then the maximum load of 10 repetitions (10 RM) was determined. The $10 \mathrm{RM}$ was repeated until the animal could not complete one set of 10 repetitions, and then the load was reduced by $500 \mathrm{~g}$. This procedure was maintained until the animal could not complete three consecutive sets, even though the charge was reduced.

\subsection{Sacrifice and Collection of Biological Material}

Collection and preparation procedures of biological material for analysis of tissue injury markers and evaluation of some of the determinant markers of oxidative stress were performed according to the methodology described by Halliwell and Gutteridge [20].

At the end of the workout, the animals were anesthetized with sodium thiopental $(40 \mathrm{mg} / \mathrm{kg}$, ip) for blood collection by cardiac puncture, and then were euthanized and decapitated. Blood was immediately centrifuged at $800 \mathrm{~g}$ for $15 \mathrm{~min}$ at $4{ }^{\circ} \mathrm{C}$, and the supernatant was stored at $-80^{\circ} \mathrm{C}$ for further analysis.

\subsection{Determination of TBARS}

An aliquot of a $20 \mu \mathrm{L}$ plasma was added to $40 \mu \mathrm{L}$ of a mixture consisting of equal parts of trichloroacetic acid (TCA), $15 \% 0.25 \mathrm{~N} \mathrm{HCl}, 0.375 \% \mathrm{TBA}, 2.5 \mathrm{mM}$ butylated hydroxytoluene (BHT), and $40 \mu \mathrm{L}$ of sodium dodecyl (SDS) at $8.1 \%$, and then it was heated at $95{ }^{\circ} \mathrm{C}$ for $30 \mathrm{~min}$. The $\mathrm{pH}$ of the mixture was 0.9. BHT was used to prevent lipid peroxidation during heating. After cooling to 
room temperature, $40 \mu \mathrm{L}$ of $\mathrm{n}$-butanol was added, and then the mixture was centrifuged at $800 \mathrm{~g}$ for $15 \mathrm{~min}$ for further evaluation by spectrophotometry [16]. As a background control, a system with $40 \mu \mathrm{L}$ formed of equal parts of $15 \%$ TCA, $0.25 \mathrm{~N} \mathrm{HCl}, 2.5 \mathrm{mM} \mathrm{BHT}$, and $40 \mu \mathrm{L}$ of $8.1 \%$ SDS was used. The spectrophotometric reading of the samples was taken at $532 \mathrm{~nm}$, representing the peak complex formed between the absorption and dialdehyde acid (TBA-MDA). A molar extinction coefficient of $150,000 \mathrm{M}^{-1} \mathrm{~cm}^{-1}$ was used [16].

\subsection{Quantification of Plasma and Muscle Total Creatine Kinase}

Acute resistance exercise involving maximum repetitions until volitional exhaustion can induce micro injuries in muscle fibers [21]. Accordingly, the activity of creatine kinase (CK) [22], the regulatory enzyme controlling the resynthesis of adenosine triphosphate (ATP), can be used as an indicator of muscle damage after an acute exercise session [22], as adopted in the present study.

For quantification, the recommendations of the commercial kit manufacturer were used (Labtest ${ }^{\circledR}$; Lagoa Santa-Minas Gerais, Brazil), where $20 \mu \mathrm{L}$ plasma from each animal was homogenized in specific reagents at $37 \pm 0.2^{\circ} \mathrm{C}$ and then read in a spectrophotometer UV/VIS at $340 \mathrm{~nm}$.

\subsection{Quantification of Lactate Dehydrogenase Total Plasma}

For the quantification of $\mathrm{LDH}$, the recommendations were used as provided by the commercial kit manufacturer (Labtest; Lagoa Santa-MG). Like CK, the levels of lactate dehydrogenase (LDH) are also susceptible to high intensity exercise stimuli, and they can be used to indicate the plasma dosage status for the intactness of the muscle membrane.

LDH is present in nearly all organs and tissues of the organism and its catalytic activity is due to the presence of several isoenzymes, which can form different patterns depending on the source of $\mathrm{LDH}$ present in the serum. In the conditions prescribed by the kit's manufacturer, LDH catalyzes the conversion of pyruvate to lactate as NADH is oxidized to NAD ${ }^{+}$. The catalytic activity is determined by the speed of NADH's disappearance. This activity was quantified according to the manufacturer's recommendations as contained in the commercial kit (Labtest ${ }^{\circledR}$ ), in which $20 \mu \mathrm{L}$ of plasma of each animal was homogenized in specific reagents at $37 \pm 0.2{ }^{\circ} \mathrm{C}$ and read on a spectrophotometer UV/VIS at $340 \mathrm{~nm}$.

\subsection{Statistical Analysis}

The results were presented as mean \pm standard error of the mean (SEM). They are considered to be statistically significant results with a probability of error less than $5 \%(p<0.05)$. Normality, homoscedasticity, and variance tests were performed simultaneously using Prism software, version 5.0 (GraphPad Software, San Diego, CA, USA). The analysis of variance (ANOVA) was used followed by a multiple comparison test, as appropriate. The EC50 (effective concentration to neutralize DPPH) was used in the in vitro tests.

\section{Results}

Based on retention time and PAD spectrum, the HEE showed an identical chromatographic behavior to the polar compounds. In this sample (Figure 2), retention time (RT) was recorded for $13 \mathrm{~min}$ and the greatest peak intensity showed a higher UV absorption at $229 \mathrm{~nm}$ (Peak A1) and a run time of $30 \mathrm{~min}$. The chromatographic analysis serves to show the complexity of the compound, which allows us to evaluate the purity of the sample; it was recorded from 250 to $350 \mathrm{~nm}$ using LC-PAD, and gives us an indication of the presence of the phenolic compounds. 

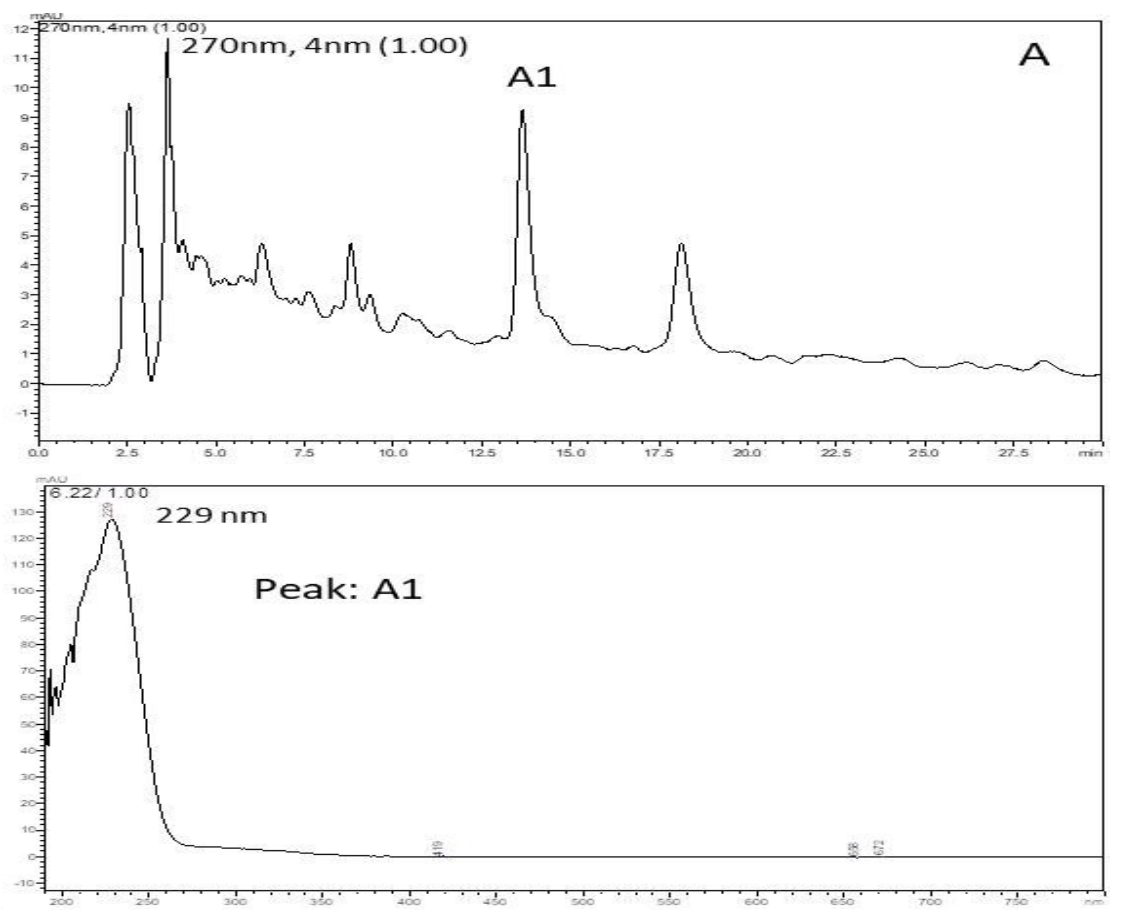

Figure 2. Chromatographic profile HPLC/PAD of the hydroethanolic extract of $C$. argyrophyllus. It shows the spectrum UV/VIS of the prominent peak (absorption band at $229 \mathrm{~nm}$ ) and retention time.

The $x$-axis is time and the $y$-axis is intensity. Thus, the figure shows that retention was recorded at $13 \mathrm{~min}$. On the other hand, there was UV absorption intensity at $229 \mathrm{~nm}$. This variation occurred during the total time of $30 \mathrm{~min}$. Therefore, during $30 \mathrm{~min}$ of execution, the absorption peak occurred at $13 \mathrm{~min}$ with an intensity of $229 \mathrm{~nm}$, with no other important values during the execution time.

The polarity, as phenolic compounds present in plant extracts, is directly related to their antioxidant potential due to the amount of hydroxyl groups [12]. The inhibitory potential (IP) was lower than the positive control gallic acid (Table 1). This parameter was confirmed with a higher $\mathrm{EC}_{50}$ value, which is the required concentration of the test compound to reduce by $50 \%$ the initial concentration of DPPH in regards to the content of the antioxidant activity index (AAI), which qualifies the samples by their strength to help neutralize the DPPH radical, according to Scherer et al. [14].

Table 1. Antioxidant activity of the hydroethanolic extract of C. argyrophyllus determined by a DPPH test.

\begin{tabular}{cccc}
\hline Samples & $\mathbf{I P} \%$ & EC $_{50}(\mu \mathrm{g} / \mathbf{m L} \pm \mathbf{S E M})$ & AAI \\
\cline { 2 - 5 } HEE & 39.79 & $243.8 \pm 0.25^{*}$ & 0.12 \\
\hline Gallicacid & 87.61 & $8.2 \pm 0.07^{*}$ & 4.87 \\
\cline { 2 - 4 } IP = inhibitory & potential; AAI = antioxidant activity index, HEE $=$ hydroethanolic extract. ${ }^{*} p<0.05$.
\end{tabular}

Values with different symbols indicate differences between the samples and gallic acid $(p<0.05)$ : HEE: hydroethanolic extract, IP\%: inhibitory potential, and $\mathrm{EC}_{50}$ : AAI: antioxidant activity index. The $\mathrm{IP} \%$ and $\mathrm{EC}_{50}$ of the sample were calculated at their respective time of $30 \mathrm{~min}$. One-way ANOVA was followed by a Tukey test $(\rho<0.05)$. The AAI classifies the sample as weak when AAI $<0.5$, moderate when $0.5<\mathrm{AAI}<1$, strong when $1>\mathrm{AAI}<2$, and very strong when IAA $>2$.

The decrease in lipid oxidation by free radicals induced by ferrous sulfate was evaluated by the reduction in the level of TBARS formation. The different concentrations applied reduced the TBARS levels compared to the negative control (Figure 3). This performance represents a lipoperoxidation inhibition of $27.4 \%(100 \mu \mathrm{g} / \mathrm{mL})$ and $28.6 \%(200 \mu \mathrm{g} / \mathrm{mL})$. 


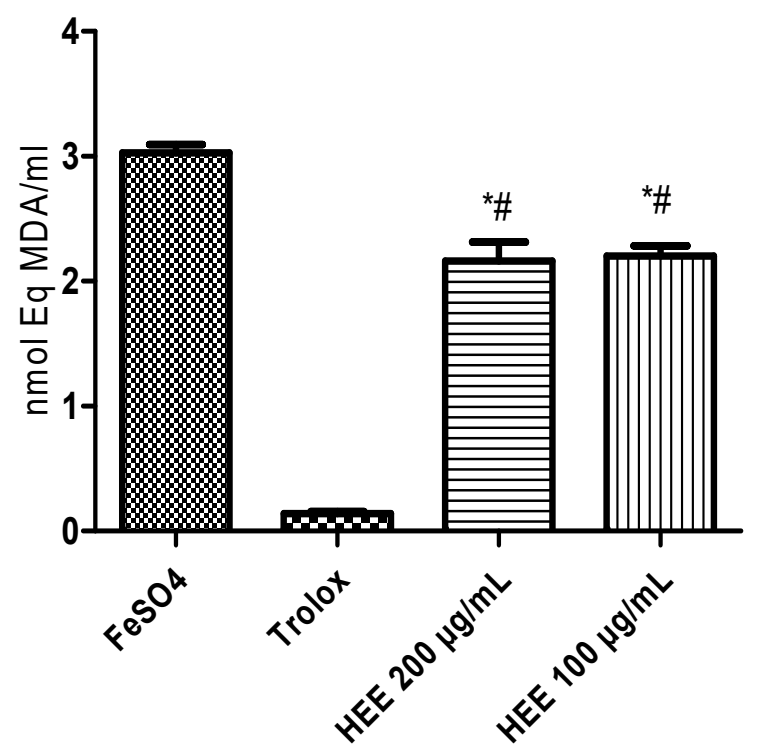

Figure 3. Inhibitory capacity of lipid peroxidation measured by the generation of malondialdehyde (MDA) induced by ferrous sulfate. * Different from the negative control $(p<0.001)$; \# Different from the positive control trolox $(p<0.0001)$.

The plasma lipid peroxidation was assessed by quantification of the TBARS, which is represented here by malondialdehyde (MDA). There were no exercise group differences in plasma MDA (Figure 4). However, when the MDA levels were measured in the gastrocnemius muscle (Figure 4), it was found there were significant differences only in the exercised group, with reduced MDA levels in animals treated with HEE, suggesting that the HEE reduced the oxidative stress induced by RE until exhaustion.
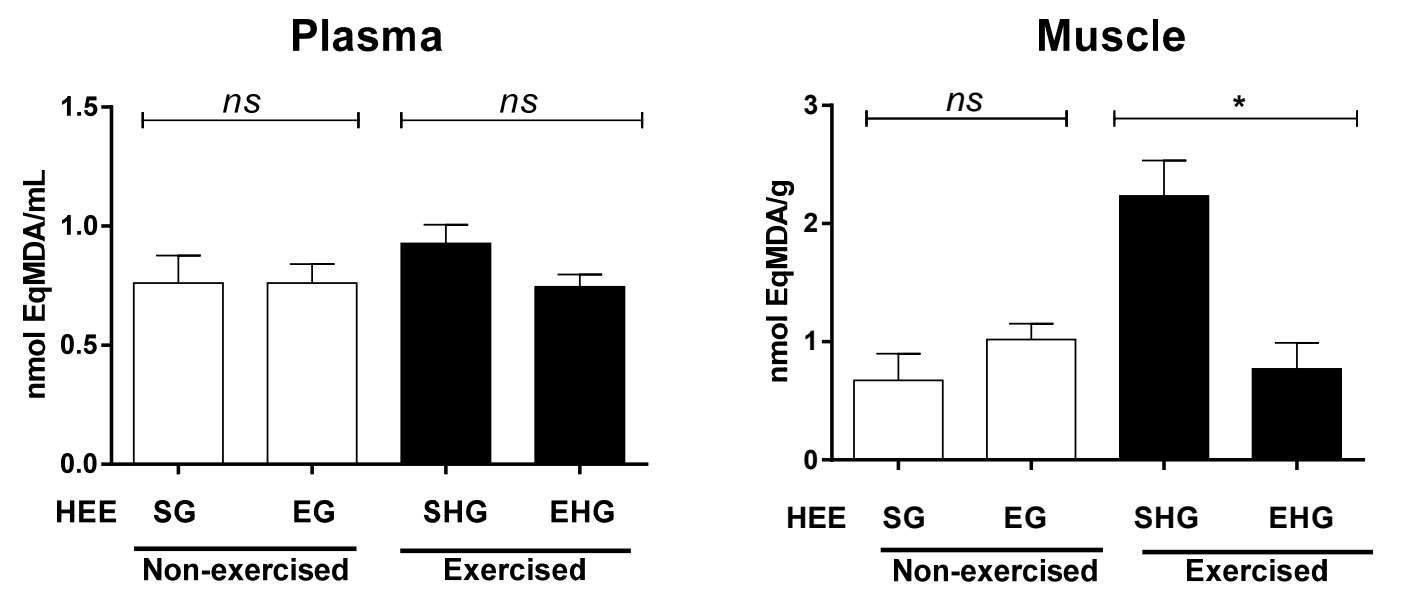

Figure 4. Concentration of malondialdehyde in animals subjected to the administration of hydroethanolic extract of $C$. argyrophyllus (EHE) and further execution of acute resistance exercise. ns: not significant; * differences between the exercised groups. The results are shown as mean \pm SEM. One-way ANOVA with a Bonferroni post test; $p<0.05$. SG—-sedentary vehicle group; EG-exercise vehicle group; SHG—sedentary group HEE; EHG—HEE exercise group.

Figure 5 illustrates the quantification of plasma CK. No significant differences were observed between the non-exercised groups, treated (HEE), or vehicle groups (Tween 80). However, the plasma concentration of CK in the exercised group treated with EHE decreased (54.13\%) compared with the exercised group treated with the vehicle only. 


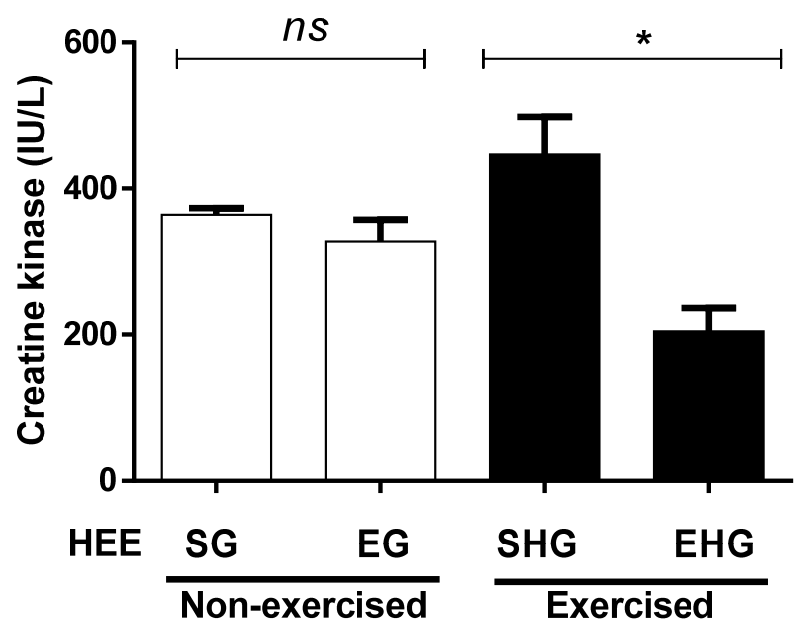

Figure 5. Plasma concentration of creatine kinase in animals exercised and subjected to the administration of hydroethanolic extract of $C$. argyrophyllus (HEE). The results are presented as mean \pm SEM and evaluated by one-way ANOVA with a Bonferroni post test; $p<0.05$. ns: not significant; ${ }^{*}$ differences between the exercised groups. SG—-sedentary vehicle group; EG—exercise vehicle group; SHG—sedentary group HEE; EHG-HEE exercise group.

The plasma concentrations of LDH are shown in Figure 6. It was found that there was a reduction in the plasma concentration of $\mathrm{LDH}(47.14 \%)$ in the non-exercised groups treated with EHE compared to vehicle. In addition, the plasma concentration of LDH in the exercised group and the one supplemented with EHE also showed a reduction (30.53\%) compared with the vehicle group exercised.

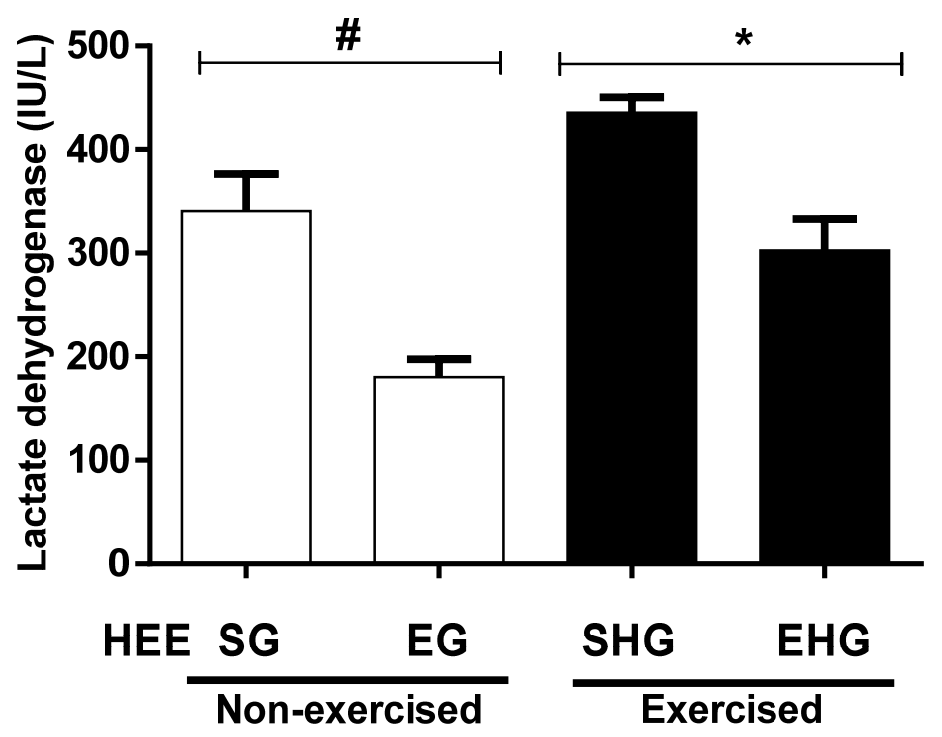

Figure 6. Evaluation of lactate dehydrogenase (LDH) plasma in animals subjected to the administration of hydroethanolic extract of $C$. argyrophyllus (HEE) and further execution of acute resistance exercise. The results are presented as mean \pm SEM and evaluated by one-way ANOVA with a Bonferroni post test; $p<0.05$. \# SG—sedentary vehicle group; EG—exercise vehicle group; SHG—sedentary group HEE; EHG-HEE exercise group.

\section{Discussion}

Hydroethanolic extract of $C$. argyrophyllus has antioxidant effects and is able to reduce the damage caused by acute sessions of RE until exhaustion. Possibly, this ability can be attributed to the compounds of a phenolic nature present in its composition $[23,24]$, as shown in the chromatographic analysis by 
HPLC. The high affinity and hydrophilicity of the compounds present in plant extracts and fractions are directly related to their antioxidant capacity due to the diverse nature of hydroxyl groups [25].

The antioxidant ability of the extract from $C$. argyrophyllus to neutralize the synthetic free radical DPPH was tested. Although the EC50 extract had a higher activity than that of the gallic acid positive control, it was comparable with Croton extracts from other species, as seen in the study by Ndhala et al. [26], which showed that C. zambesicus's EC50 was $1018 \mu \mathrm{g} / \mathrm{mL}$. Regarding the IP\%, HEE from C. argyrophyllus met the same standards found by Furlan et al. [24] in nine species of Croton from Argentina.

This effect of the extract of $C$. argyrophyllus is important because lipid peroxidation is involved in the ROS reaction with the polyunsaturated fatty acid constituents of cell membranes, which can change the lipid structures, proteins, carbohydrates, and DNA, as well as present carcinogenic, mutagenic, and protein denaturant properties $[27,28]$.

In previous studies $[7,26]$, the ability of Croton extracts to resist against lipid peroxidation has been tested, which was corroborated in the present study where the generation of malondialdehyde was significantly inhibited. With the confirmation of the antioxidant capacity of $C$. argyrophyllus extract, it was possible to assess the extract's ability to reduce the damage caused by a session of resistance training. Exercise, when done exhaustively or at intensities above the body's organic capabilities, can be an inducer of ROS production [10]. In a study by Coombes et al. [29], due to the supplementation with antioxidants, they found low levels of oxidative stress, although the production of contractile force was reduced. This evidence can be explained by the reduced generation of MDA, which is a product that can damage the lipid membranes of the muscles. However, in that present study, there was no evaluation of the absolute levels of force in the exercised groups.

Several substances in the extract, such as phenols and terpenoids, synergistically may present redox activity in their electron donor groups [25], although this effect has not been observed at plasma levels. Thus, there are possibilities to use other dosages in future studies, beyond those used here, in addition to chronic supplementation.

The adaptation to exercise favors greater stabilization of the cell membrane when subjected to stress. This is due, among other factors, to the homeostasis in the synthesis and resynthesis of ATP for reducing the oxidative damage [30], which can be covered by supplementing with antioxidants and nutrients that can be turned into energy-rich substrates.

As seen in this study, administration of HEE to rats that performed high-intensity RE provided a lower plasma concentration of $\mathrm{CK}$, which can be justified by the mechanism related to cellular energy homeostasis [2] when considering the case of acute exercise, which does not provide for adaptation to physical stress. Although the CK levels were above the reference values, this may not always indicate that there are histological lesions in the muscle fiber membrane [31,32], and the consensus that it does not adapt to high load exercise is the basis for the impairment of the permeability of the cell membrane, thereby increasing serum levels of CK.

In addition to CK, elevated plasma LDH is an important biomarker of muscle damage induced by exhaustive exercise. Increases in serum LDH can also be a reflection of the production of ROS. The ROS are metabolites resulting from exercise, and one of the factors involved in reducing the contractile activity and causing muscle fatigue [33] when they are above the organic capacity for neutralization. In this sense, supplementation with extracts rich in antioxidant compounds can exert greater cellular resistance against oxidative stress [34], increase the activity of antioxidant enzymes, or stabilize the free radicals generated.

\section{Conclusions}

Regardless of whether it is a complex sample in which the predominant compounds are not fully identified, although chromatographic analysis has pointed to the presence of flavonoids, the HEE C. argyrophyllus showed an ability to partially reduce the biomarkers of oxidative stress at the plasma level and in the muscle. Taking into account CK and LDH activities, the HEE was able to induce 
reductions. These results provide a new perspective for the use of compounds derived from medicinal plants to prevent or combat muscle damage. For a better redox protection, it is necessary to use more purified fractions.

The design of this research was a limiting factor in the present study, as the evaluations were made only at the end of the intervention. Given that the tests are performed by the sacrifice of the animals, it does not allow for initial evaluation. Therefore, further research with initial data is important as a way to obtain a better experimental design for the study.

Author Contributions: Conceptualization, S.S.d.A., F.J.A. and D.G.d.M., D.M.M., A.L.J.; data curation, A.N.d.S.; formal analysis, J.L.d.S., R.M.d.S., M.M.T. and L.M.V.S.; investigation, S.S.d.A. and F.J.A.; methodology, A.C.M.; project administration, S.S.d.A., and C.d.S.E.; resources, S.S.d.A.; supervision, C.d.S.E.; writing一original draft, S.S.d.A., F.J.A., and D.G.d.M.; writing—review and editing, C.S.d.E., G.M.D., A.L.G.C., R.G.d.S.

Funding: This research received no external funding.

Conflicts of Interest: The authors declare no conflict of interest.

\section{References}

1. Raymond, M.J.; Bramley-Tzerefos, R.E.; Jeffs, K.J.; Winter, A.; Holland, A.E. Systematic Review of High-Intensity Progressive Resistance Strength Training of the Lower Limb Compared with Other Intensities of Strength Training in Older Adults. Arch. Phys. Med. Rehab. 2013, 94, 1458-1472. [CrossRef]

2. Cruzat, V.F.; Rogero, M.M.; Borges, M.C.; Tirapegui, J. Current aspects about oxidative stress, physical exercise and supplementation. Braz. J. Sports. Med. 2007, 13, 336-342.

3. Reid, M.B. Invited Review: Redox modulation of skeletal muscle contraction: What we know and what we don't. J. Appl. Physiol. 2001, 90, 724-731. [CrossRef] [PubMed]

4. Reid, M.B.; Khawli, F.A.; Moody, M.R. Reactive oxygen in skeletal muscle. III. Contractility of unfatigued muscle. J. Appl. Physiol. 1993, 75, 1081-1087. [CrossRef] [PubMed]

5. Aoi, W.; Naito, Y.; Takanami, Y.; Kawai, Y.; Sakuma, K.; Ichikawa, H. Oxidative stress and delayed-onset muscle damage after exercise. Free Radic. Biol. Med. 2004, 37, 480-487. [CrossRef] [PubMed]

6. Powers, S.K.; Jackson, M.J. Exercise-induced oxidative stress: Cellular mechanisms and impact on muscle force production. Physiol. Rev. 2008, 88, 1243-1276. [CrossRef] [PubMed]

7. Dos Santos, J.L.; Dantas, R.E.; Lima, C.A.; De Araújo, S.S.; De Almeida, E.C.; Marçal, A.C. Protective effect of a hydroethanolic extract from Bowdichiavirgilioides on muscular damage and oxidative stress caused by strenuous resistance training in rats. J. Int. Soc. Sports Nutr. 2014, 11, 58. [CrossRef]

8. Kumar, M.; Chandel, M.; Kaur, P. Chemical composition and inhibitory effects of water extract of Henna leaves on reactive oxygen species, DNA scission and proliferation of cancer cells. EXCLI J. 2016, 15, 842-857.

9. Zhang, D.; Hamauzu, Y. Phenolics, ascorbic acid, carotenoids and antioxidant activity of broccoli and their changes during conventional and microwave cooking. Food Chem. 2004, 88, 503-509. [CrossRef]

10. Antunes-Neto, J.M.F.; Silva, L.P.; Macedo, D.V. Oxidative Stress Biomarkers: New Possibilities of Monitoring in Physical Training. Braz. J. Sci. Mov. 2005, 13, 73-80.

11. Albuquerque, U.P.; Muniz de Medeiros, P.; de Almeida, A.L.; Monteiro, J.M.; Machado de Freitas Lins Neto, E.; Gomes de Melo, J.; dos Santos, J.P. Medicinal plants of the caatinga (semi-arid) vegetation of NE Brazil: A quantitative approach. J. Ethnopharmacol. 2007, 114, 325-354. [CrossRef] [PubMed]

12. Dias, P.V.S.; Arthuso, F.S.; Oliveira, J.E.; Suzuki, M.F.; Sousa, J.M.; Soares, C.R.J. Determination of recombinant Interferon- $\alpha 2$ in E. coli periplasmic extracts by reversed-phase high-performance liquid chromatography. J. Chromatogr. B Analyt. Technol. Biomed. Life Sci. 2018, 1072, 193-198. [CrossRef] [PubMed]

13. Souza, C.; Medeiros, C.; Silva, L.; Silveira, T.; Silveira, P.; Pinho, C. Serum measurement of muscle and oxidative damage in soccer players after a game. Braz. J. Cinean. Hum. Perf. 2010, 12, 269-274.

14. Scherer, R.; Wagner, R.; Duarte, M.C.T.; Godoy, H.T. Composition and antioxidant and antimicrobial activities of clove, citronella and palmarosa essential oils. Braz. J. Med. Plants 2009, 11, 442-449.

15. Ohkowa, H.; Ohisi, N.; Yagi, K. Assay for lipid peroxides in animals tissue by thiobarbituric acid reaction. Anal. Biochem. 1979, 95, 351-358. [CrossRef] 
16. Lapenna, D.; Ciofani, G.; Pierdomenico, S.D.; Giamberardino, M.A.; Cuccurullo, F. Reaction condictions affecting the relationship between thiobarbituric acid reactivity and lipid preoxides in human plasma. Free Radic. Biol. Med. 2001, 31, 331-335. [CrossRef]

17. Sanocka, D.; Kurpisz, M. Reactive oxygen species and sperm cell. Reprod. Biol. Endocrinol. 2004, 2, $245-251$. [CrossRef]

18. Tamaki, T.; Uchiyama, S.; Nakano, S. A weight-lifting exercise model for inducing hypertrophy in the hindlimb muscles of rats. Med. Sci. Sport Exer. 1992, 24, 881-886. [CrossRef]

19. Barauna, V.G.; Batista, M.L.; Costa-Rosa, L.F.; Casarini, D.E.; Krieger, J.E.; Oliveira, E.M. Cardiovascular adaptations in rats submitted to a resistance-training model. Clin. Exp. Pharmacol. 2005, 32, $249-254$. [CrossRef]

20. Halliwell, B.; Gutteridge, J.M.C. Role of free radicals and catalytic metal ions in human disease. Met. Enzimol. 1990, 186, 128-132.

21. Hartmann, U.; Mester, J. Training and overtraining markers in selected sport events. Med. Sci. Sports Exerc. 2000, 32, 209-215. [CrossRef] [PubMed]

22. Yang, Y.C.; Kao, L.S. Regulation of sodium-calcium exchanger activity by creatine kinase. Adv. Exp. Med. Biol. 2013, 961, 163-173. [PubMed]

23. Tepe, B.; Daferera, D.; Tepe, A.S.; Polissiou, M.; Sokmen, A. Antioxidant activity of the essential oil and various extracts of Nepeta flavida Hub.-Mor. from Turkey. Food Chem. 2007, 103, 1358-1364. [CrossRef]

24. Furlan, C.M.; Santos, K.P.; Sedano-Partida, M.D.; Motta, L.B.; Santos, D.Y.; Salatino, A. Flavonoids and antioxidant potential of nine Argentinian species of Croton (Euphorbiaceae). Braz. J. Bot. 2015, 38, 693-702. [CrossRef]

25. Budini, P.; Petronilho, F.C.; Citadini-Zanette, V.; Marcondes, C.; Zoch, A.N.; Reginatto, F.H. Preliminary Studies of the Antioxidant Activity of the Hydroethanolic Extract of Young and Adult Leaves of Tabebuia heptaphylla. Lat. Am. J. Pharm. 2007, 26, 394-398.

26. Ndhlala, A.R.; Aderogba, M.A.; Ncube, B.; Van Staden, J. Anti-Oxidative and Cholinesterase Inhibitory Effects of Leaf Extracts and Their Isolated Compounds from Two Closely Related Croton Species. Molecules 2013, 18, 1916-1932. [CrossRef]

27. Bar-Or, D.; Bar-Or, R.; Rael, L.T.; Brody, E.N. Oxidative stress in severe acute illness. Redox Biol. 2015, 12, 340-345. [CrossRef]

28. Hall, E.D.; Wang, J.A.; Bosken, J.M.; Singh, I.N. Lipid Peroxidation in Brain or Spinal Cord Mitochondria After Injury. Bioenerg. Biomembr. 2016, 48, 169-174. [CrossRef]

29. Coombes, J.S.; Rowell, B.; Dodd, S.L.; Demirel, H.A.; Naito, H.; Shanely, R.A. Effects of vitamin E deficiency on fatigue and muscle contractile properties. Eur. J. Appl. Physiol. 2002, 87, 272-277. [CrossRef]

30. Souza, T.; Apel, M.; Bordignon, S.; Matzenbacher, N.; Zuanazzi, J.; Henriques, A. Chemical composition and antioxidant activity of the volatile oil from Eupatorium polystachyum. Braz. J. Pharm. 2007, 17, 368-372. [CrossRef]

31. Ale, B.; Qin, Y.; Singh, A.B. The Significance of Elevated Serum Enzyme Creatine Kinase as a Biomarker in Musculoskeletal Injury: A Review. Imp. J. Interd. Res. 2017, 3, 184-189.

32. Koch, A.J.; Pereira, R.; Machado, M. The creatine kinase response to resistance exercise. J. Musculoskelet. Neuronal. Interact. 2014, 14, 68-77. [PubMed]

33. Alessio, H.M.; Hagerman, A.E.; Fulkerson, B.; Ambrose, J.; Rice, R.; Wiley, R.L. Generation of reactive oxygen species after exhaustive aerobic and isometric exercise. Med. Sci. Sport Exer. 2000, 32, 1576-1581. [CrossRef] [PubMed]

34. Peternelj, T.T.; Coombes, J.S. Antioxidant Supplementation during Exercise Training Antioxidant Supplementation during Exercise Training. Sports Med. 2011, 41, 1043-1069. [CrossRef] [PubMed]

(C) 2019 by the authors. Licensee MDPI, Basel, Switzerland. This article is an open access article distributed under the terms and conditions of the Creative Commons Attribution (CC BY) license (http://creativecommons.org/licenses/by/4.0/). 